\title{
Worker Protection Standard: What Workers and Handlers Need to Know 1
}

Frederick M. Fishel ${ }^{2}$

The Worker Protection Standard (WPS) is a Federal regulation designed to protect agricultural workers (people involved in the production of agricultural plants) and pesticide handlers (people mixing, loading, or applying pesticides or doing other tasks involving direct contact with pesticides). It has been in full implementation since 1995. A complete reference for the WPS is provided by: How to Comply with the Worker Protection Standard for Agricultural Pesticides: What Employers Need to Know http://www.epa.gov/agriculture/epa-735-b-05002.pdf.

\section{Basic responsibilities}

Worker employers. Worker employers must make sure that workers have been trained about general pesticide safety (Figure 1). This includes workers who enter treated areas on the farm, forest, nursery, or greenhouse during a restricted-entry interval to perform WPS-permitted tasks.
Handler employers. Handler employers must make sure that handlers are trained about general pesticide safety and about correct ways to handle pesticides (Figure 2).

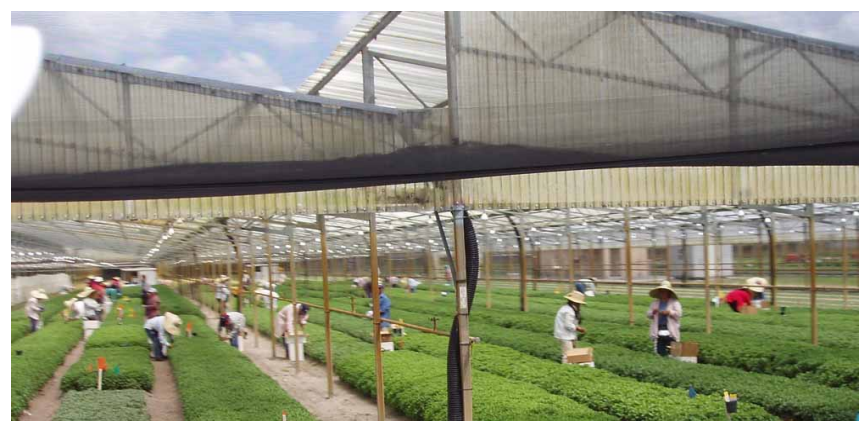

Figure 1. Agricultural workers are required to have pesticide safety training.

\section{Untrained workers}

Agricultural establishment owners are responsible to provide basic pesticide safety information to untrained workers before they enter treated areas on the establishment where, within 30

1. This document is PI-114, one of a series of the Pesticide Information Office, Florida Cooperative Extension Service, Institute of Food and Agricultural Sciences, University of Florida. Original publication date April 2006. Visit the EDIS Web Site at http://edis.ifas.ufl.edu.

2. Frederick M. Fishel, associate professor, Agronomy Department, and Director, Pesticide Information Office; Florida Cooperative Extension Service, Institute of Food and Agricultural Sciences, University of Florida, Gainesville, FL 32611.

The use of trade names in this publication is solely for the purpose of providing specific information. UF/IFAS does not guarantee or warranty the products named, and references to them in this publication does not signify our approval to the exclusion of other products of suitable composition. Use pesticides safely. Read and follow directions on the manufacturer's label.

The Institute of Food and Agricultural Sciences (IFAS) is an Equal Opportunity Institution authorized to provide research, educational information and other services only to individuals and institutions that function with non-discrimination with respect to race, creed, color, religion, age, disability, sex, sexual orientation, marital status, national origin, political opinions or affiliations. U.S. Department of Agriculture, Cooperative Extension Service, University of Florida, IFAS, Florida A. \& M. University Cooperative Extension Program, and Boards of County Commissioners Cooperating. Larry Arrington, Dean 


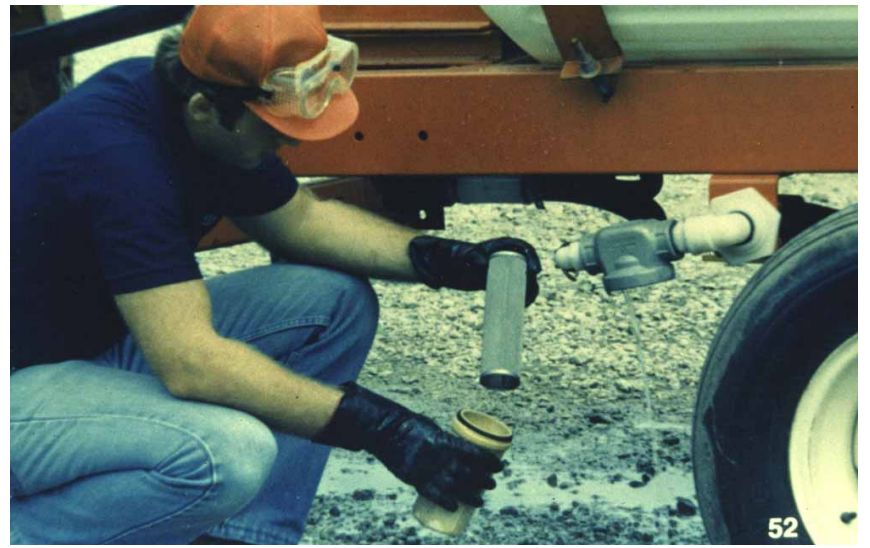

Figure 2. Adjusting application equipment is considered a handling task and requires training.

days, a pesticide has been applied or a restricted-entry interval has been in effect. Owners are required to:

- Provide the basic pesticide safety information in a manner that untrained workers can understand, such as through written materials, oral communication, or other means.

- Be able to verify that they provided the workers with the required basic pesticide safety information.

- Provide workers with at least the following information:

- Pesticides may be on plants, soil, irrigation water, or drifting from nearby applications.

- To prevent pesticides from entering the body:

- Follow directions and/or signs about keeping out of treated or restricted areas.

- Wash before eating, drinking, using chewing gum or tobacco, or using the toilet.

- Wear work clothing that protects the body from pesticide residues.

- Wash/shower with soap and water, shampoo hair, and put on clean clothes after work.
- Wash work clothes separately from other clothes before wearing them again.

- Wash immediately in the nearest clean water if pesticides are spilled or sprayed on the body and then - as soon as possible - shower, shampoo, and change into clean clothes.

\section{Who must be trained?}

Each worker and handler must be trained. This requirement is met if the worker or handler:

- Has been trained within the last 5 years as a WPS handler or WPS worker, even if he or she has changed employers; or

- Is currently a certified applicator of restricted-use pesticides; or

- Is currently trained as a handler who works under the supervision of a certified pesticide applicator.

\section{How soon must they be trained?}

- Handlers must be trained before they do any handling task.

- Early-entry workers who will contact anything that has been treated with the pesticide which caused the restricted-entry interval must be trained before they do any early-entry task on the establishment.

- Other agricultural workers, including early-entry workers who will not contact anything that has been treated with the pesticide which caused the restricted-entry interval must be trained before they accumulate more than 5 separated days of entry into treated areas on the establishment where, within the past 30 days, a pesticide has been applied or a restricted-entry interval has been in effect. These 5 days of entry need not be consecutive and are not limited to a growing season or calendar year.

Note: owners must provide untrained workers with basic pesticide safety information before they enter into treated areas on the establishment where, within the past 30 days, a pesticide has 
been applied or a restricted-entry interval

has been in effect (see section on

"Untrained workers").

\section{How often must handlers and workers be trained?}

Handlers and workers must be trained at least once every 5 years, counting from the end of the month in which the previous training was completed.

\section{Additional information}

How to Comply with the Worker Protection Standard for Agricultural Pesticides: What Employers Need to Know. United States Environmental Protection Agency. Revised 2005.

http://www.epa.gov/agriculture/epa-735-b-05-002.pdf

UF/IFAS EDIS Worker Protection Standard Topic Menu. http://edis.ifas.ufl.edu/TOPIC_WPS. 